\title{
In vitro and in vivo antimalarial activity of puberulic acid and its new analogs, viticolins A-C, produced by Penicillium sp. FKI-4410
}

\author{
Masato Iwatsuki ${ }^{1}$, Shohei Takada ${ }^{2}$, Mihoko Mori ${ }^{2,3}$, Aki Ishiyama ${ }^{1}$, Miyuki Namatame ${ }^{1}$, Aki Nishihara-Tsukashima ${ }^{1}$, \\ Kenichi Nonaka ${ }^{3}$, Rokuro Masuma ${ }^{2,3}$, Kazuhiko Otoguro ${ }^{1}$, Kazuro Shiomi ${ }^{2,3}$ and Satoshi Ōmura ${ }^{3}$ \\ In the course of screening for antimalarial agents, five tropolone compounds were isolated from the culture broth of Penicillium \\ sp. FKI-4410. Two were known compounds, puberulic acid and stipitatic acid. Three were new analogs of puberulic acid, \\ designated viticolins A-C. Among them, puberulic acid exhibited potent antimalarial inhibition, with $\mathrm{IC}_{50}$ values of $0.01 \mu \mathrm{g} \mathrm{ml}^{-1}$ \\ against chloroquine-sensitive and -resistant Plasmodium falciparum strains in vitro. Furthermore, puberulic acid showed weak \\ cytotoxicity against human MRC-5 cells, with an $\mathrm{IC}_{50}$ value of $57.2 \mu \mathrm{g} \mathrm{ml} \mathrm{I}^{-1}$. The compound also demonstrated a therapeutic \\ effect in vivo, which compared well against the currently used antimalarial drugs, and thus shows promise as a leading \\ candidate for development into a new antimalarial compound.
}

The Journal of Antibiotics (2011) 64, 183-188; doi:10.1038/ja.2010.124; published online 10 November 2010

Keywords: antimalarial activity; Penicillium sp.; puberulic acid; viticolin

\section{INTRODUCTION}

Malaria, caused by Plasmodium species, remains a major global health problem, generating over 243 million clinical cases and causing 863000 deaths in 2008. ${ }^{1}$ Many antimalarial agents have been developed, but resistance to them develops quickly and is now widespread. Currently, the World Health Organization (WHO) recommends artemisinin combination therapy for antimalarial treatment. However, resistance to the recently introduced artemisinin class of drugs has been reported. ${ }^{2}$ Therefore, the development of new, safe and potent antimalarial drugs, with new modes of action and structural features, is urgently required.

In the course of our screening program to discover antimalarial drugs from metabolites of microorganisms, which are active against drug-resistant parasites in vitro and in vivo, we have discovered various microbial metabolites with potent antimalarial properties. ${ }^{3-8}$ Recently, we have isolated some tropolone compounds from a culture broth of Penicillium sp. FKI-4410. These compounds are puberulic acid $(\mathbf{1})^{9,10}$ and stipitatic acid (2), ${ }^{11}$ along with three new analogs, designated viticolins A-C (3-5) (Figure 1).

Puberulic acid (1) exhibited potent and selective antimalarial activity in vitro and in vivo, whereas the others showed moderate or weak activity in vitro. We report herein, the fermentation, isolation, structure elucidation and antimalarial profiles of $\mathbf{1}$ and its analogs and compared with those of the clinically used antimalarial drugs, artemisinin, artesunate and chloroquine. We also report some significant observations with respect to the structure-activity relationship of $\mathbf{1}$.

\section{RESULTS}

Taxonomy of the producing strain FKI-4410

The producing organism, strain FKI-4410, was considered as a new species belonging to the genus Penicillium and was designated as Penicillium viticola sp. nov. The sequence of $\beta$-tubulin and calmodulin genes of this new species was deposited at the DNA Data Bank of Japan, with accession numbers AB540174 and AB540173, respectively. Taxonomic details will be reported elsewhere. ${ }^{12}$

\section{Fermentation}

The typical time course of fermentation for production of puberulic acid (1) and its analogs in a 30-1 jar fermenter is shown in Figure 2. All compounds were produced only in the sup. Production of 1 was detected at day 3 , reaching a max. $\left(75 \mathrm{mg} \mathrm{l}^{-1}\right)$ at day 6 , slowly decreasing thereafter to $30 \mathrm{mgl}^{-1}$. In comparison, production of stipitaitc acid (2) and viticolin A (3) increased gradually, reaching a peak of 26 and $40 \mathrm{mg}^{-1}$ at days 10 and 9 , respectively. Other minor components, such as viticolins B (4) and C (5), could not be detected under this condition.

\section{Isolation}

The isolation procedure for $\mathbf{1 - 5}$ is summarized in Scheme 1. The 10day-old culture broth (15l) was centrifuged. The sup. was passed through a Sepabeads SP207 column $(100 \phi \times 160 \mathrm{~mm}$, Mitsubishi Chemical, Tokyo, Japan) previously equilibrated with $\mathrm{H}_{2} \mathrm{O}$ containing $0.1 \%$ TFA. After washing with $40 \% \mathrm{MeOH}$ aq. soln with $0.1 \% \mathrm{TFA}$

${ }^{1}$ Research Center for Tropical Diseases, Kitasato Institute for Life Sciences, Kitasato University, Tokyo, Japan; ${ }^{2}$ Graduate School of Infection Control Sciences, Kitasato University, Tokyo, Japan and ${ }^{3}$ Kitasato Institute for Life Sciences, Kitasato University, Tokyo, Japan

Correspondence: Dr K Otoguro or Professor K Shiomi, Kitasato Institute for Life Sciences, Kitasato University, 5-9-1 Shirokane, Minato-ku, Tokyo 108-8641, Japan. E-mail: otoguro@lisci.kitasato-u.ac.jp or shiomi@lisci.kitasato-u.ac.jp

Received 21 June 2010; revised 9 September 2010; accepted 12 October 2010; published online 10 November 2010 
(3.51), the active materials were eluted with a mixture of $100 \% \mathrm{MeOH}$ containing $0.1 \%$ TFA (3.51). The whole eluate was concd in vacuo and dried by blowing $\mathrm{N}_{2}$ gas to give a brown material $(8.0 \mathrm{~g})$. The material

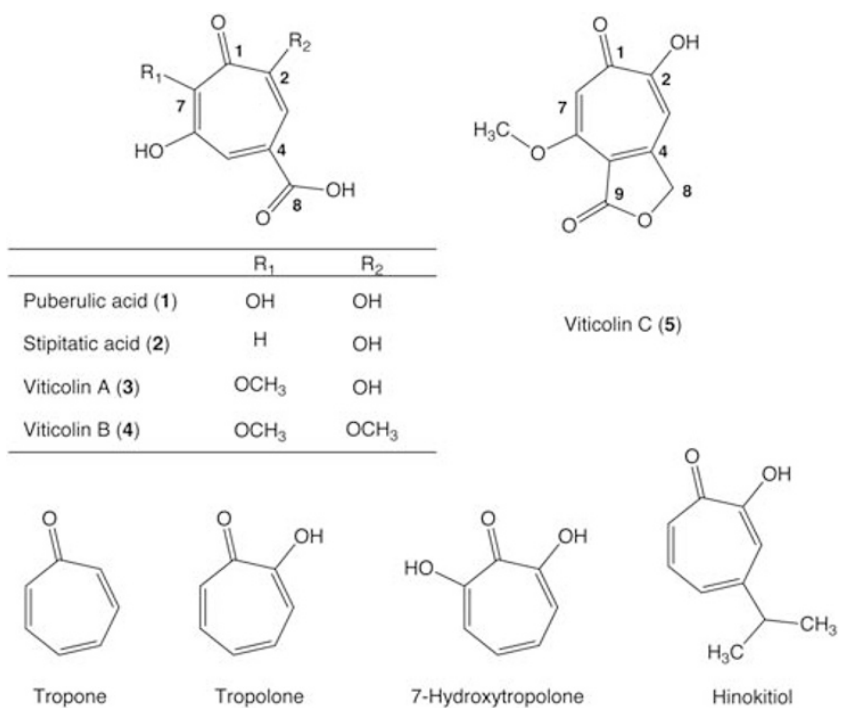

Figure 1 Structures of puberulic acid (1), stipitatic acid (2), viticolins A-C (3-5) and other tropones.

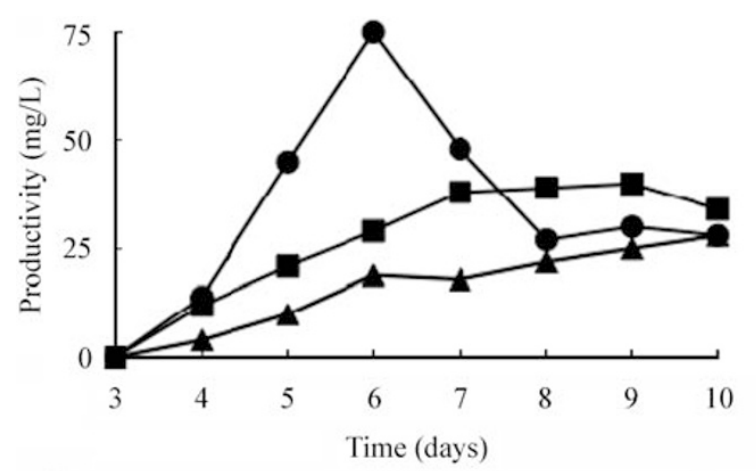

Puberulic acid (1) - Viticolin A (3) $₫$ Stipitatic acid (2)

Figure 2 Typical time course of fermentation of Penicillium sp. FKI-4410. was dissolved in a small amount of $\mathrm{H}_{2} \mathrm{O}$ containing $0.1 \%$ TFA and passed through an ODS column $(40 \phi \times 160 \mathrm{~mm}$, Senshu Scientific, Tokyo, Japan) previously equilibrated with $\mathrm{H}_{2} \mathrm{O}$ containing $0.1 \%$ TFA. After washing with $\mathrm{H}_{2} \mathrm{O}$ containing $0.1 \%$ TFA $(100 \mathrm{ml})$, the active materials were eluted with $10 \% \mathrm{CH}_{3} \mathrm{CN}$ aq. soln containing $0.1 \%$ TFA $(60 \mathrm{ml} \times 10)$. The sixth eluate fraction $(60 \mathrm{ml})$ was crystallized at $4{ }^{\circ} \mathrm{C}$ and the crude crystals $(197 \mathrm{mg})$ were separated by decantation. We purified $105 \mathrm{mg}$ of the crude crystal by HPLC using a Pegasil ODS column $(20 \phi \times 250 \mathrm{~mm}$, Senshu Scientific) with $25 \% \mathrm{MeOH}$ aq. soln with $0.1 \%$ TFA at $8 \mathrm{ml} \mathrm{min}^{-1}$ detected by UV at $270 \mathrm{~nm}$. The retention times of puberulic acid (1), stipitatic acid (2) and viticolins A-C (3-5) were 32, 47, 53, 39 and $22 \mathrm{~min}$, respectively (Figure 3). Each active fraction was concd and freeze-dried to give $1(5.3 \mathrm{mg}), 2(5.6 \mathrm{mg})$, $3(7.7 \mathrm{mg}), 4(3.1 \mathrm{mg})$ and $\mathbf{5}(3.0 \mathrm{mg})$ as yellow powders.

\section{Structure elucidation}

The physico-chemical properties of the isolated compounds 1-5 are summarized in Table 1. They are readily soluble in $\mathrm{MeOH}$ or DMSO but insoluble in $\mathrm{CHCl}_{3}$. The characteristic absorption at UV $270 \mathrm{~nm}$ and the IR absorptions at 1260-1294, 1535-1581, 1593-1633 and $3410-3433 \mathrm{~cm}^{-1}$ suggested the presence of a hydroxytropolone moiety. ${ }^{13}$ The strong IR absorption of $\mathbf{1 - 4}$ at $1699-1720 \mathrm{~cm}^{-1}$ suggested they contain carboxyl groups.

The molecular formulae of $\mathbf{1}$ and $\mathbf{2}$ were elucidated by HR-FAB-MS to be $\mathrm{C}_{8} \mathrm{H}_{6} \mathrm{O}_{6}$ and $\mathrm{C}_{8} \mathrm{H}_{6} \mathrm{O}_{5}$, respectively. The NMR spectral data of $\mathbf{1}$ revealed a symmetrical hydroxytropolone, consisting of four resolved aromatic carbon and one carboxyl carbon signals (Table 2). In comparison with reported data, 1 was identified as puberulic acid ${ }^{11}$ and $\mathbf{2}$ as stipitatic acid. ${ }^{14}$

The structure elucidation of the other compounds was carried out by comparison of spectroscopic data obtained for 1 . The molecular formula of 3 was elucidated by HR-ESI-MS to be $\mathrm{C}_{9} \mathrm{H}_{8} \mathrm{O}_{6}$, indicating that $\mathbf{3}$ has one additional methyl unit compared with $\mathbf{1}$. From comparison of the ${ }^{1} \mathrm{H}$ and ${ }^{13} \mathrm{C}$ NMR spectra of 3 and 1 , the signals of one methoxy group appeared in 3 (Table 2) and the HMBC correlations from the methoxy proton $\left(\delta_{\mathrm{H}} 3.94\right)$ and $s p^{2}$ methine proton of $5-\mathrm{H}$ $\left(\delta_{\mathrm{H}} 7.83\right)$ to the oxygenated $s p^{2}$ quaternary aromatic carbon of C-7 $\left(\delta_{\mathrm{C}} 152.0\right)$ proved that 3 was a new 7-O-methyl analog of $\mathbf{1}$, as shown in Figure 4, and now designated as viticolin A.

The molecular formula of 4 was elucidated by HR-EI-MS to be $\mathrm{C}_{10} \mathrm{H}_{10} \mathrm{O}_{6}$, indicating that 4 has two additional methyl units when compared with 1 . From comparison of the ${ }^{1} \mathrm{H}$ and ${ }^{13} \mathrm{C}$ NMR spectra

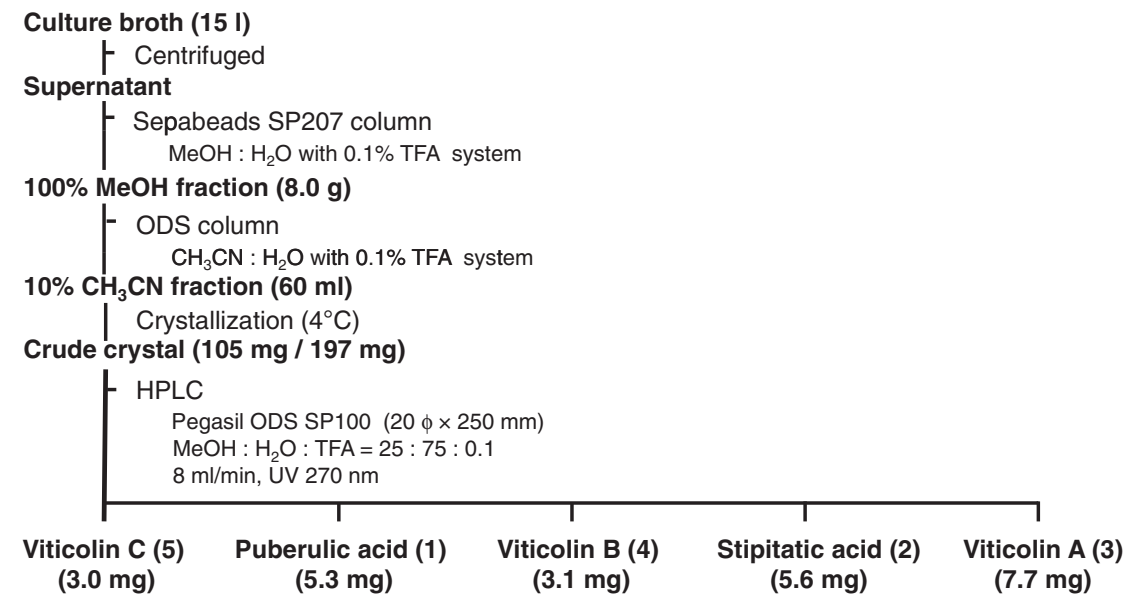

Scheme 1 Isolation procedure of $\mathbf{1 - 5}$. 
of 4 and 1, the signals of two methoxy groups appeared in 4 (Table 2). The 10 resolved carbon signals indicated that 4 might be either an unsymmetrical 2,7-O-dimethyl or 6,7-O-dimethyl analog of 1 , but not a symmetrical 2,6-O-dimethyl or 1,7-O-dimethyl analog. The HMBC correlations from a methoxy proton $\left(\delta_{\mathrm{H}} 3.97\right)$ and $s p^{2}$ methine proton of $3-\mathrm{H}\left(\delta_{\mathrm{H}} 7.55\right)$ to the oxygenated $s p^{2}$ quaternary aromatic carbon of C-2 $\left(\delta_{\mathrm{C}} 162.4\right)$ and from a methoxy proton $\left(\delta_{\mathrm{H}} 3.87\right)$ and $s p^{2}$ methine proton of $5-\mathrm{H}\left(\delta_{\mathrm{H}} 7.85\right)$ to the oxygenated $s p^{2}$ quaternary aromatic carbon of C-7 $\left(\delta_{\mathrm{C}} 151.0\right)$ revealed that 4 is a new 2,7-O-dimethyl

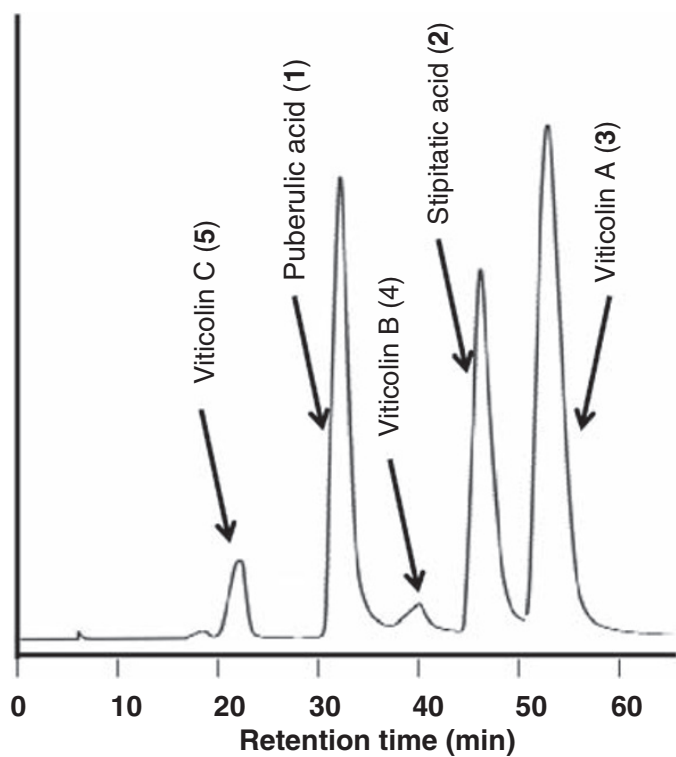

Figure 3 Purification of $\mathbf{1 - 5}$ by HPLC. The detailed conditions of HPLC are described in 'Results'. analog of puberulic acid, as shown in Figure 1, and now designated as viticolin B (Figure 4).

The molecular formula of $\mathbf{5}$ was elucidated by HR-FAB-MS to be $\mathrm{C}_{10} \mathrm{H}_{8} \mathrm{O}_{5}$, requiring seven degrees of unsaturation. The IR absorption at $1753 \mathrm{~cm}^{-1}$ suggested the presence of a lactone ring. The ${ }^{1} \mathrm{H}$ and ${ }^{13} \mathrm{C}$ NMR spectral data of 5 are listed in Table 2. The ${ }^{13} \mathrm{C}$ NMR, HMQC and HMBC spectra indicated 10 carbons, which were classified into seven aromatic carbons of a tropolone skeleton, one ester carbonyl carbon at $\delta_{\mathrm{c}} 170.1$, one oxygenated $s p^{3}$ methylene carbon at $\delta_{\mathrm{c}} 70.3$ and one methoxy carbon at $\delta_{\mathrm{c}} 57.1$, thus, accounting for six degrees of unsaturation. Therefore, the remaining degree of unsaturation should be because of a ring structure. The HMBC correlations from the oxygenated $s p^{3}$ methylene proton of $8-\mathrm{H}_{2}\left(\delta_{\mathrm{H}} 5.10\right)$ to the $s p^{2}$ quaternary aromatic carbon signal of C-4 at $\delta_{\mathrm{C}} 158.2$ and C-5 at $\delta_{\mathrm{C}}$ 110.2 and ester carbonyl carbon of C-9 $\left(\delta_{\mathrm{C}} 170.1\right)$ confirmed the presence of an $\alpha, \beta$-unsaturated $\gamma$-lactone ring. The HMBC correlations from the $s p^{2}$ methine proton of 7-H $\left(\delta_{\mathrm{H}} 6.59\right)$ to two oxygenated $s p^{2}$ quaternary aromatic carbons of C-6 $\left(\delta_{\mathrm{C}} 169.1\right)$ and C-2 $\left(\delta_{\mathrm{C}} 163.3\right)$ and the $s p^{2}$ quaternary aromatic carbon signal of C-5, from the $s p^{2}$ methine proton of $3-\mathrm{H}\left(\delta_{\mathrm{H}} 6.47\right)$ to one oxygenated $s p^{2}$ quaternary aromatic carbons of $\mathrm{C}-2$, the $s p^{2}$ quaternary aromatic carbon signal of C-5 and the $s p^{3}$ methylene carbon signal of C-8 $\left(\delta_{\mathrm{C}} 70.3\right)$ and from a methoxy proton $\left(\delta_{\mathrm{H}} 3.75\right)$ to $\mathrm{C}-6$ revealed that an $\alpha, \beta$-unsaturated $\gamma$-lactone ring was fused with a 6-O-methytropolone ring, as shown in Figure 4. This structure was confirmed by the NOE correlations between the methoxy proton and $\mathrm{H}-7$, and between $\mathrm{H}-3$ and $\mathrm{H}_{2}-8$. Thus, the structure of $\mathbf{5}$ was determined to be another new analog of $\mathbf{1}$, designated as viticolin $\mathrm{C}$.

\section{Antimalarial activity in vitro}

Table 3 shows the in vitro antimalarial activities of the isolated compounds, together with some other known tropone compounds and some std antimalarial drugs. Puberulic acid (1) showed significant potent and

Table 1 Physico-chemical properties of viticolins A-C (3-5), puberulic acid (1) and stipitatic acid (2)

\begin{tabular}{|c|c|c|c|c|c|}
\hline & Viticolin A (3) & Viticolin $B(4)$ & Viticolin C (5) & Puberulic acid (1) & Stipitatic acid (2) \\
\hline Appearance & Yellow powder & Yellow powder & Yellow powder & Yellow powder & Yellow powder \\
\hline Molecular formula & $\mathrm{C}_{9} \mathrm{H}_{8} \mathrm{O}_{6}$ & $\mathrm{C}_{10} \mathrm{H}_{10} \mathrm{O}_{6}$ & $\mathrm{C}_{10} \mathrm{H}_{8} \mathrm{O}_{5}$ & $\mathrm{C}_{8} \mathrm{H}_{6} \mathrm{O}_{6}$ & $\mathrm{C}_{8} \mathrm{H}_{6} \mathrm{O}_{5}$ \\
\hline MW & 212 & 226 & 208 & 198 & 182 \\
\hline EI-MS $(m / z)$ & & $226\left[\mathrm{M}^{+}\right]$ & & & \\
\hline FAB-MS $(m / z)$ positive & & & $209[\mathrm{M}+\mathrm{H}]^{+}$ & & \\
\hline FAB-MS $(m / z)$ negative & & & & $197[\mathrm{M}-\mathrm{H}]^{-}$ & $181[\mathrm{M}-\mathrm{H}]^{-}$ \\
\hline ESI-MS $(m / z)$ negative & $211[\mathrm{M}-\mathrm{H}]^{-}$ & & & & \\
\hline \multicolumn{6}{|l|}{$H R-M S(m / z)$} \\
\hline Calcd. & 211.0243 & 226.0478 & 209.0450 & 197.0087 & 181.0144 \\
\hline Found & 211.0235 & 226.0478 & 209.0447 & 197.0085 & 181.0137 \\
\hline $\mathrm{UV} \lambda_{\max }^{\mathrm{MeOH}} \mathrm{nm}(\varepsilon)$ & $\begin{array}{c}270(19720) \\
345(5300)\end{array}$ & $\begin{array}{c}270(10620) \\
350(3840)\end{array}$ & $\begin{array}{c}252(18510) \\
349(6650)\end{array}$ & $\begin{array}{l}268(49500) \\
368(10300)\end{array}$ & $\begin{array}{c}270(13320) \\
350(4140)\end{array}$ \\
\hline $\mathrm{IR} v_{\max }^{\mathrm{KBr}} \mathrm{cm}^{-1}$ & $\begin{array}{l}3431,1711,1622 \\
1574,1529,1385 \\
1294,1248,1194\end{array}$ & $\begin{array}{c}3423,1718,1629 \\
1581.1442,1385 \\
1260,1209\end{array}$ & $\begin{array}{c}3431,1753,1686 \\
1620,1601,1554, \\
1541,1483,1427 \\
1367,1350,1279 \\
1225,1171\end{array}$ & $\begin{array}{c}3410,1699,1593 \\
1535,1392,1348 \\
1290,1217\end{array}$ & $\begin{array}{l}3433,1720,1633 \\
1579,1454,1383 \\
1288,1211,1072\end{array}$ \\
\hline \multicolumn{6}{|l|}{ Solubility } \\
\hline Soluble & $\mathrm{MeOH}$ & $\mathrm{MeOH}$ & DMSO & $\mathrm{MeOH}, \mathrm{DMSO}$ & $\mathrm{MeOH}$ \\
\hline Slightly soluble & $\mathrm{CH}_{3} \mathrm{CN}$, acetone & $\mathrm{CH}_{3} \mathrm{CN}$ & $\mathrm{H}_{2} \mathrm{O}, \mathrm{MeOH}, \mathrm{CH}_{3} \mathrm{CN}$ & $\mathrm{H}_{2} \mathrm{O}, \mathrm{CH}_{3} \mathrm{CN}$, acetone & $\mathrm{CH}_{3} \mathrm{CN}$ \\
\hline Insoluble & $\mathrm{CHCl}_{3}$ & $\mathrm{CHCl}_{3}$ & $\mathrm{CHCl}_{3}$ & $\mathrm{CHCl}_{3}$ & $\mathrm{CHCl}_{3}$ \\
\hline
\end{tabular}


Table $2{ }^{1} \mathrm{H}$ and ${ }^{13} \mathrm{C}$ NMR spectral data of viticolins A-C (3-5), puberulic acid (1) and stipitatic acid (2)

\begin{tabular}{|c|c|c|c|c|c|c|c|c|c|c|}
\hline \multirow[b]{2}{*}{ Position } & \multicolumn{2}{|c|}{ Viticolin A (3) } & \multicolumn{2}{|c|}{ Viticolin $B(4)^{a}$} & \multicolumn{2}{|c|}{ Viticolin $C(5)^{b}$} & \multicolumn{2}{|c|}{ Puberulic acid (1) } & \multicolumn{2}{|c|}{ Stipitatic acid (2) } \\
\hline & ${ }^{13} \mathrm{C}$ & ${ }^{1} H(J$ in $\mathrm{Hz})$ & ${ }^{13} \mathrm{C}$ & ${ }^{1} H(J$ in $H z)$ & ${ }^{13} \mathrm{C}$ & ${ }^{1} H(J$ in $H z)$ & ${ }^{13} \mathrm{C}$ & ${ }^{1} H(J$ in $H z)$ & ${ }^{13} \mathrm{C}$ & ${ }^{1} \mathrm{H}(\mathrm{J}$ in $\mathrm{Hz})$ \\
\hline 2 & 163.8 & - & 162.4 & - & 163.3 & - & 155.4 & - & $165.9^{d}$ & - \\
\hline $2-\mathrm{OCH}_{3}$ & - & - & 56.9 & $3.97(3 \mathrm{H}, \mathrm{s})$ & - & - & - & - & - & - \\
\hline 3 & 111.0 & $7.72(1 \mathrm{H}, \mathrm{s})$ & 109.8 & $7.55(1 \mathrm{H}, \mathrm{s})$ & 110.1 & $6.47(1 \mathrm{H}, \mathrm{s})$ & 119.3 & $7.96(1 \mathrm{H}, \mathrm{s})$ & 113.4 & $7.62(1 \mathrm{H}, \mathrm{s}$ \\
\hline 6 & 161.0 & - & 158.0 & - & 169.1 & - & 155.4 & - & $169.3^{d}$ & - \\
\hline $6-\mathrm{OCH}_{3}$ & - & - & - & - & 57.1 & $3.75(3 \mathrm{H}, \mathrm{s})$ & - & - & - & - \\
\hline 7 & 152.0 & - & 151.0 & - & 114.2 & $6.59(1 \mathrm{H}, \mathrm{s})$ & 159.4 & - & 117.4 & $6.95(1 \mathrm{H}, \mathrm{s}$ \\
\hline 7- $\mathrm{OCH}_{3}$ & 58.8 & $3.94(3 \mathrm{H}, \mathrm{s})$ & 60.1 & $3.87(3 \mathrm{H}, \mathrm{s})$ & - & - & - & - & - & - \\
\hline 8 & 167.0 & - & 168.8 & - & 70.3 & $5.10(2 \mathrm{H}, \mathrm{s})$ & 167.4 & - & 168.5 & - \\
\hline 9 & - & - & - & - & 170.1 & - & - & - & - & - \\
\hline
\end{tabular}

a Measured in $\mathrm{CD}_{3} \mathrm{OD}$.

${ }^{b}$ Measured in DMSO- $d_{6}+5 \% \mathrm{CD}_{3} \mathrm{OH}$.

cMeasured in acetone- $d_{6}$.

dExchangable.

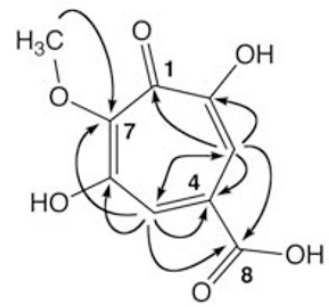

Viticolin A (3)

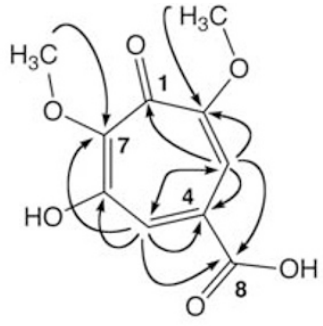

Viticolin B (4)

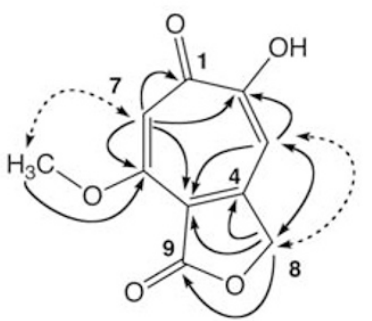

Viticolin C (5)

Figure $4 \mathrm{HMBC}$ and NOE correlations in viticolins A-C (3-5).

Table 3 In vitro antimalarial activity against Plasmodium falciparum K1 and FCR3 strains, and cytotoxicity against MRC-5 cells of puberulic acid (1), stipitatic acid (2), viticolins A-C (3-5), selected tropone compounds and some commonly-used antimalarial drugs

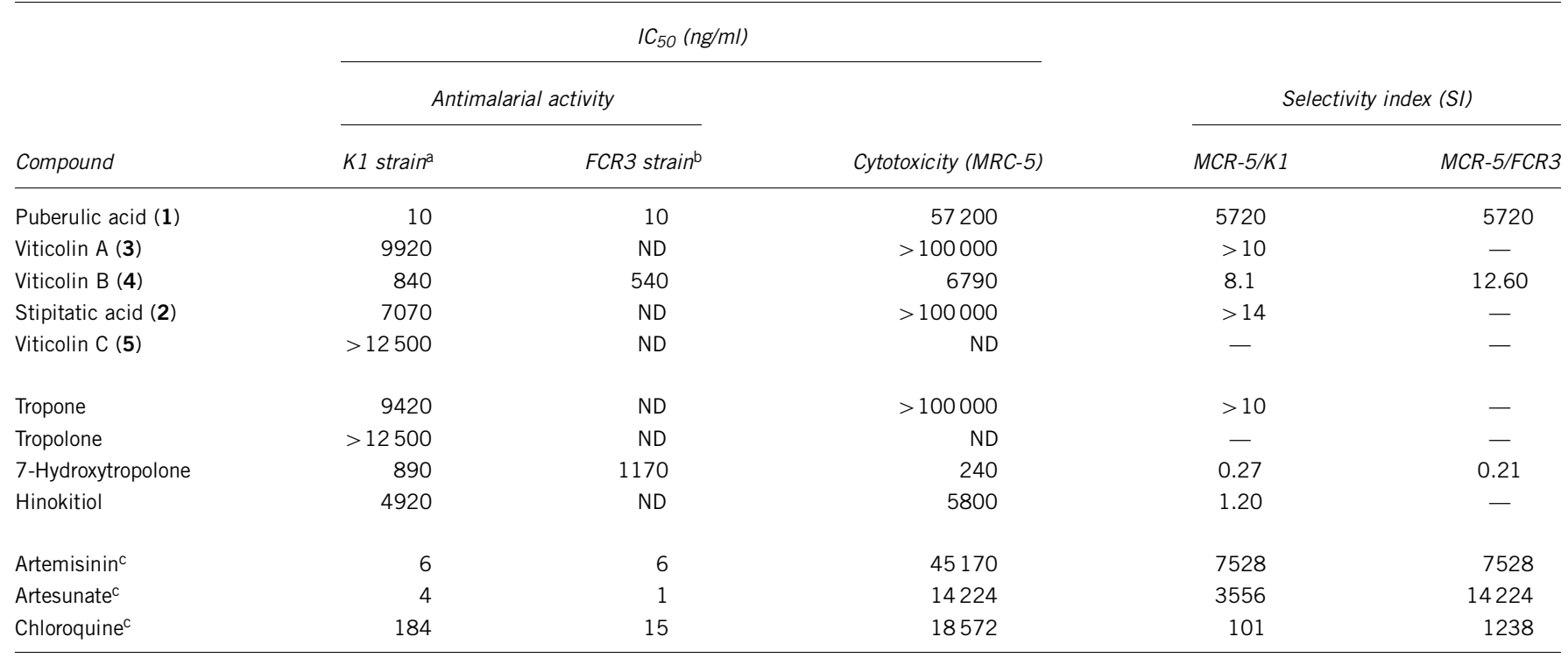

Abbreviation: ND, not determined.

${ }^{a}$ Chloroquine-resistant strain.

${ }^{b}$ Chloroquine-sensitive strain.

'Drugs commonly used to treat malaria. 
uniform activity against both the chloroquine-resistant K1 strain and the chloroquine-sensitive FCR3 strain of $P$. falciparum. Antimalarial activity against both $\mathrm{K} 1$ and FCR3 strains was identical $\left(0.01 \mu \mathrm{g} \mathrm{ml}^{-1}\right)$. The activity of 1 against the $\mathrm{K} 1$ strain was of the same order as that of artemisinin or artesunate. The antimalarial properties of all other compounds tested were relatively weak. Against the K1 strain, viticolin B (4) and 7-hydroxytropolone showed $\mathrm{IC}_{50}$ values of 0.84 and $0.89 \mu \mathrm{g} \mathrm{ml}^{-1}$, respectively. Viticolin A (3), stipitatic acid (2), tropone and hinokitiol had even weaker antimalarial activity, in the range of $5-10 \mu \mathrm{g} \mathrm{ml}^{-1}$. Viticolin C (5) and tropolone did not show any antimalarial activity.

Among the tropolones tested, Barnard et al. ${ }^{15}$ have previously reported the $\mathrm{IC}_{50}$ values of hinokitiol and tropolone against a clone NC-1 of the FCB strain of $P$. falciparum were 0.5 and $3.7 \mu \mathrm{g} \mathrm{ml}^{-1}$, respectively. Explanation for the differences between the two sets of results may be because of either the different assay conditions or the different Plasmodium strains used.

The cytotoxicities of the tested compounds are also depicted in Table 3. The isolated compounds and tropones had weak $\left(\mathrm{IC}_{50}=\right.$ 5-60 $\mu \mathrm{g} \mathrm{ml}^{-1}$ ) or no cytotoxicity, except 7-hydroxytropolone $\left(\mathrm{IC}_{50}=0.24 \mu \mathrm{g} \mathrm{ml}^{-1}\right)$. To evaluate the combined antimalarial activities and cytotoxicities, we introduced a selectivity index (cytotoxicity $\left(\mathrm{IC}_{50}\right.$ for the MRC-5 cells)/ antimalarial activity $\left(\mathrm{IC}_{50}\right.$ for the $\mathrm{K} 1$ strain or the FCR-3 strain)), as depicted in Table 3. Puberulic acid (1) showed a relatively high selectivity index of 5720, irrespective of parasite strain, significantly greater than that shown by chloroquine, indicating that the compound holds significant promise as an antimalarial lead. Of all the other compounds tested, none exhibited a favorable selectivity index.

\section{Antimalarial activity in vivo}

Preliminary in vivo antimalarial activities of $\mathbf{1}$ and the std antimalarial drugs, injected s.c., were measured in a mouse model, using the rodent malaria P. berghei $\mathrm{N}$ strain, which is chloroquine-sensitive. A dose of $2 \mathrm{mg} \mathrm{kg}^{-1}$ of 1 suppressed $69 \%$ of malaria parasites. Under the same experimental conditions, the $\mathrm{ED}_{50}$ values of artesunate and chloroquine were 1.7 and $1.5 \mathrm{mg} \mathrm{kg}^{-1}$, respectively This initial finding that the in vivo s.c. antimalarial activity of $\mathbf{1}$ is similar to both artesunate and chloroquine confirms that puberulic acid shows substantial promise as a lead antimalarial compound.

\section{DISCUSSION}

We isolated puberulic acid (1), stipitatic acid (2) and structurally related new compounds, viticolins A-C (3-5). The in vitro antimalarial and cytotoxic studies of these five compounds, together with some other known tropone compounds, provided valuable insight into structure-activity relationships.

The hydroxy group at C-7 of puberulic acid appears to be an important moiety for antimalarial activity. Compounds 3 and 4, possessing a methoxy group at C-7, and 2, which lacks a hydroxy group at C-7, were 1,000-, 80- and 700-fold less active than 1, respectively. Moreover, 7-hydroxytropolone, which has a hydroxy group at C-7, was 14-fold more active than tropolone. The carboxylic group at C-4 of puberulic acid appears to be important with respect to selectivity. Compounds 1 and 2, each with a carboxylic group at C-4, showed a better selectivity index than 7-hydroxytropolone and hinokitiol. The methoxy group at C-2 of 3 also seems to improve antimalarial activity. Compound $\mathbf{3}$ has a hydroxy group at $\mathrm{C}-2$ and is 12 -fold less active than 4 . This might indicate that a $2-O$-methyl analog of $\mathbf{1}$ would have more potent antimalarial activity than $\mathbf{1}$. Further studies are necessary to understand more comprehensively the detailed structure-activity relationships of 1 and its analogs.
It is known that $\mathbf{1}$ possesses inhibitory activity against Grampositive bacteria. ${ }^{16}$ In general, the natural and synthetic tropolones have been reported to show antibacterial, antifungal, insecticidal, antiviral and antitumor activities, as well as inhibiting enzymes such as aminoglycoside- $2^{\prime \prime}$-O-adenyltransferase, ${ }^{17}$ metalloprotease ${ }^{18}$ and HIV-1 reverse transcriptase-associated ribonuclease H. ${ }^{19}$ The inhibitory mechanisms of tropolones were thought to reflect their ability to form a complex with divalent cations. ${ }^{20}$ Among these compounds, hinokitiol and its related synthetic derivatives have been reported to show antimalarial activity, whereas the synthetic benzotropolone derivatives ${ }^{15,21,22}$ and a dihydrotroplone antibiotic, cordytropolone, ${ }^{23}$ have also been reported to show moderate or weak antimalarial activities in vitro. However, this paper represents the first report of the antimalarial activity of carboxytropolones, such as puberulic acid.

The above results indicate that puberulic acid is a promising lead compound for development of a new antimalarial drug. Further investigation, including extensive in vivo testing, of the antimalarial potential of $\mathbf{1}$ is in progress.

\section{METHODS}

\section{General experiment and compounds}

NMR spectra were measured on a Varian XL-400 spectrometer (Varian, Palo Alto, CA, USA) with ${ }^{1} \mathrm{H}$ NMR at $400 \mathrm{MHz}$ and ${ }^{13} \mathrm{C}$ NMR at $100 \mathrm{MHz}$ or a Varian Inova 600 spectrometer with ${ }^{1} \mathrm{H}$ NMR at $600 \mathrm{MHz}$ and ${ }^{13} \mathrm{C}$ NMR at $150 \mathrm{MHz}$. The chemical shifts were expressed in p.p.m. and were referenced to the solvent, $\left(\mathrm{CD}_{3}\right)_{2} \mathrm{CO}$ (2.05 p.p.m.), $\mathrm{CD}_{3} \mathrm{OD}$ (3.30 p.p.m.) or $\left(\mathrm{CD}_{3}\right)_{2} \mathrm{SO}$ (2.50 p.p.m.) in the ${ }^{1} \mathrm{H}$ NMR spectra and referenced to the solvent, $\left(\mathrm{CD}_{3}\right)_{2} \mathrm{CO}$ (29.8 p.p.m.), $\mathrm{CD}_{3} \mathrm{OD}$ (49.0 p.p.m.) or $\left(\mathrm{CD}_{3}\right)_{2} \mathrm{SO}$ (39.5 p.p.m.) in the ${ }^{13} \mathrm{C}$ NMR spectra. FAB-MS and ESI-MS spectra were measured on a JEOL JMS AX-505 HA-MS (JEOL, Akishima, Japan) and a JEOL AccuTOF apparatus. IR spectra $(\mathrm{KBr})$ were taken on a Horiba FT-210 FT IR spectrometer (Horiba, Kyoto, Japan). UV spectra were measured with a Beckman DU640 spectrophotometer (Beckman, Fullerton, CA, USA). Tropone group compounds, tropone, tropolone and hinokitiol, were purchased from Sigma (Sigma-Aldrich, St Louis, MO, USA). The compound 7-hydroxytropolone was provided by Dr Shinichi Kondo (Bioscience Associates, Tokyo, Japan).

\section{Fermentation}

Strain FKI-4410, isolated from a fruit of grape produced in Yamanashi, Japan, was grown and maintained on an agar slant consisting of $0.1 \%$ glycerol, $0.08 \%$ $\mathrm{KH}_{2} \mathrm{PO}_{4}, 0.02 \% \mathrm{~K}_{2} \mathrm{HPO}_{4}, 0.02 \% \mathrm{MgSO}_{4} \cdot 7 \mathrm{H}_{2} \mathrm{O}, 0.02 \% \mathrm{KCl}, 0.2 \% \mathrm{NaNO}_{3}$, $0.02 \%$ yeast extract and $1.5 \%$ agar (adjusted to $\mathrm{pH} 6.0$ before sterilization). A loopful of spores of the strain was inoculated into $100 \mathrm{ml}$ of the seed medium consisting of $2.0 \%$ glucose, $0.5 \%$ Polypepton (Nihon Pharmaceutical, Tokyo, Japan), $0.2 \%$ yeast extract, $0.2 \% \mathrm{KH}_{2} \mathrm{PO}_{4}, 0.05 \% \mathrm{MgSO}_{4} \cdot 7 \mathrm{H}_{2} \mathrm{O}$ and $0.1 \%$ agar (adjusted to pH 6.0 before sterilization) in each of two 500-ml Erlenmeyer flasks. The flasks were incubated on a rotary shaker $\left(210\right.$ r.p.m.) at $27^{\circ} \mathrm{C}$ for 3 days. For production of $\mathbf{1}$ and its analogs, a $200-\mathrm{ml}$ portion of the seed culture was transferred to a 30-1 jar fermenter containing 151 of production medium (3.0\% sucrose, $3.0 \%$ soluble starch, $2.0 \%$ malt extract, $0.3 \%$ Ebios, $0.5 \%$ $\mathrm{KH}_{2} \mathrm{PO}_{4}$ and $0.5 \% \mathrm{MgSO}_{4} \cdot 7 \mathrm{H}_{2} \mathrm{O}$ (adjusted to $\mathrm{pH} 6.0$ before sterilization)), and fermentation was carried out at $27^{\circ} \mathrm{C}$ for 10 days with aeration $\left(81 \mathrm{~min}^{-1}\right)$. The time courses of productivity from the sup.(s) of $\mathbf{1}-\mathbf{3}$ were measured by HPLC analysis during fermentation.

\section{Assay of antimalarial activity in vitro and in vivo}

In vitro activities against Plasmodium falciparum strains K1 (chloroquine resistant) and FCR3 (chloroquine sensitive) and cytotoxicity against human diploid embryonic cell line MRC-5 were measured, as described previously. ${ }^{3}$ A mouse model using a malaria-derived strain of $P$. berghei $\mathrm{N}$ (chloroquine sensitive) was used to assess in vivo antimalarial activity, as described previously. ${ }^{3,4}$ Test compounds were solubilized in 10\% DMSO-Tween 80 aq. soln and administered s.c. to mice $2 \mathrm{~h}$ after infection with parasites (day 0 ). The individual compound was then successively administered (s.c.) to the infected mice once a day for 3 days (days 1-3). One day after the last treatment (day 4), 
thin blood films were made from the tail blood of the mice and parasitaemia was determined, as described previously. ${ }^{4}$

\section{ACKNOWLEDGEMENTS}

This study was supported, in part, by funds from the Quality Assurance Framework of Higher Education from the Ministry of Education, Culture, Sports, Science and Technology (MEXT) in Japan, and the All Kitasato Project Study. We are grateful to Ms Hitomi Sekiguchi and Mr Toshiaki Furusawa for their technical assistance and to Ms Akiko Nakagawa, Dr Kenichiro Nagai and Ms Noriko Sato, School of Pharmacy, Kitasato University for measurements of mass and NMR spectra. We also thank Dr Shinichi Kondo (Bioscience Associates) for providing 7-hydroxytropolone.

1 World Health Organization. World Malaria Report 2009 (World Health Organization, Geneva, 2009.

2 Dondorp, A. M et al. Artemisinin resistance in Plasmodium falciparum malaria. New Engl. J. Med. 361, 455-467 (2009).

3 Otoguro, K. et al. Potent antimalarial activities of polyether antibiotic, X-206. J. Antibiot. 54, 658-663 (2001).

4 Otoguro, K. et al. In vitro and in vivo antimalarial activities of monoglycoside polyether antibiotic, K-41 against drug resistant strains of Plasmodia. J. Antibiot 55, 832-834 (2002).

5 Otoguro, K. et al. In vitro antimalarial activities of the microbial metabolites. J. Antibiot. 56, 322-324 (2003).

6 Otoguro, K. et al. In vitro and in vivo antimalarial activities of a non-glycoside 18membered macrolide antibiotic, borrelidin against drug-resistant strains of Plasmodia. J Antibiot. 56, 727-729 (2003).

7 Otoguro, K. et al. In vitro and in vivo antimalarial activities of a carbohydrate antibiotic, prumycin, against drug-resistant strains of Plasmodia. J. Antibiot. 57, 400-402 (2004).

$8 \mathrm{Ui}, \mathrm{H}$. et al. Selective and potent in vitro antimalarial activities found in four microbial metabolites. J Antibiot. 60, 220-222 (2007).
9 Birkinshaw, J. H. \& Raistrick, H. Studies in the biochemistry of micro-organisms. XXIII Puberulic acid $\mathrm{C}_{8} \mathrm{H}_{6} \mathrm{O}_{6}$ and an acid $\mathrm{C}_{8} \mathrm{H}_{4} \mathrm{O}_{6}$, new products of the metabolism of glucose by Penicllium puberulum Bainler and Penicillium aurantio-virens Biourge. With an appendix on certain dihydroxybenzenecarboxylic acids. Biochem. J. 26, 441-453 (1932).

10 Barger, J. \& Dorrer, O. Chemical properties of puberulic acid, $\mathrm{C}_{8} \mathrm{H}_{6} \mathrm{O}_{6}$, and a yellow acid $\mathrm{C}_{8} \mathrm{H}_{4} \mathrm{O}_{6}$. Biochem. J. 28, 11-15 (1934).

11 Bahwell, M. G., Collis, M. P., Mackay, M. F. \& Richards, S. L. cis-Dihydrocatechols as precursors to highly oxygenated troponoids. Part 2. Regiocontrolled syntheses of stipitatic and puberulic acids. J. Chem. Soc. Perkin Trans. 1. 13, 1913-1920 (1993).

12 Nonaka, K. et al. Penicillium viticola, a new anamorphic species isolated from a grape in Yamanashi, Japan. Mycoscience (submitted).

13 Aulin-Erdtman, G. \& Theorell, H. Studies in the tropolone series. III. Infra-red spectra. Acta Chem. Scand. 4, 1490-1494 (1950).

14 O'Sullivan, M. C. \& Schwab, J. M. Verification of the mechanism of oxidative ring expansion in the biosynthesis of stipitatic acid by Talaromyces stipitatus. Bioorg. Chem. 23, 131-143 (1995).

15 Barnard, J. F., Jagt, D. L. V. \& Honek, J. F. Small molecule probes of glyoxalase I and glyoxalase II. Biochem. Biophys. Acta. 1208, 127-135 (1994).

16 Oxford, A. E., Raistrick, H. \& Smith, G. Anti-bacterial substances from moulds. Part VI. Puberulic acid, $\mathrm{C}_{8} \mathrm{H}_{6} \mathrm{O}_{6}$, and puberolonic acid, $\mathrm{C}_{8} \mathrm{H}_{4} \mathrm{O}_{6}$, metabolic products of a number of species of Penicillium. Chem. Ind. 61, 485-487 (1942).

17 Allen, N. E., Alborn, W. E., Hobbs, J. N. \& Kirst, H. A. 7-Hydroxytropolone: an inhibitor of aminoglycoside-2"-O-adenylyltransferase. Antimicrob. Agents Chemother. 22, 824-831 (1982).

18 Morita, Y. et al. Biological activity of tropolone. Biol. Pharm. Bull. 26, 1487-1490 (2003).

19 Budihas, S. R. et al. Selective inhibition of HIV-1 reverse transcriptase-associated ribonuclease $\mathrm{H}$ activity by hydroxylated tropolones. Nucleic Acids Res. 33, 12491256 (2005).

20 Bentley, R. A fresh look at natural tropolonoids. Nat. Prod. Rep. 25, 118-138 (2008).

21 Ren, H. et al. Design, synthesis, and biological evaluation of a series of simple and novel potential antimalarial compounds. Bioorg. Med. Chem. Lett. 11, 1851-1854 (2001).

22 Khrizman, A. et al. Synthesis and in vitro protozoocidal evaluation of novel diazabicyclic tropolone derivatives. Arch. Pharm. Chem. Life Sci. 340, 569-576 (2007).

23 Seephonkai, P. et al. A new tropolone from the insect pathogenic fungus Cordyceps sp. BCC 1681. J. Antibiot. 54, 751-752 (2001) 